\title{
LAND SURFACE ENERGY BALANCE OF OASIS-DESERT ECOTONE AND ITS RELATIONSHIP WITH SURFACE TEMPERATURE DURING THE SUMMER
}

\author{
LI, L. ${ }^{1,2}-$ YAN, R. ${ }^{1^{*}}-$ XIONG, H. ${ }^{3}$ \\ ${ }^{1}$ State Key Laboratory of Lake Science and Environment, Nanjing Institute of Geography and \\ Limnology, Chinese Academy of Sciences, 210008 Nanjing, China \\ ${ }^{2}$ University of Chinese Academy of Sciences, 100049 Beijing, China \\ ${ }^{3}$ College of Arts and Sciences of Beijing Union University, 100083 Beijing, China \\ *Corresponding author \\ e-mail:rhyan@niglas.ac.cn \\ (Received $16^{\text {th }}$ Jun 2018; accepted $10^{\text {th }}$ Aug 2018)
}

\begin{abstract}
In this study, land surface energy balance in the oasis-desert ecotone of the northern piedmont of the East Tianshan Mountains, Xinjiang, China was calculated using meteorological data from a Bowen ratio system, in conjunction with modified Bowen ratio method. The daily variation in land surface energy balance was then investigated, along with energy partitioning under different weather conditions. The four weather conditions including sunny day, overcast day, rainy day and average condition. Finally, based on the analysis of relationship between land surface energy and land surface temperature, prediction models for land surface temperature were constructed and validated. The results show that the splendens grassland soil has a cache energy function. Latent heat $(L E)$ plays a dominant role in the energy budget of the oasis-desert zone for all weather conditions, which is inconsistent with some previous studies on other arid areas. The average value of $L E / R n(59 \%)$ of this zone is between those of the desert and of the oasis due to the transitional thermal-hydrologic property of the land surfaces and the local circulation. The variations of energy partitioning during the daytime are the same among the different weather conditions, while these curves fluctuate continuously at night, especially before sunrise and after sunset. Except for $H$, the correlations between each energy component and the surface temperature for different conditions are ordered as follows: clear days > average values> overcast days > rainy days. The same rule is also found in the response intensities (regression coefficients) of the land surface temperature to energy change. The established and validated models for land surface temperature suggest that the soil surface layer temperature is mainly influenced by dry heat energy factors $(R n, G$, and $H)$ because of not in the summer monsoon zone and coarser soil particle, rather than the hygrothermal energy factor $(L E)$.
\end{abstract}

Keywords: Bowen ratio, latent heat, sensible heat, energy budget, temperature, Xinjiang

\section{Introduction}

Land surface processes describe the exchange of matter and energy between the earth surface and the atmosphere, which closely connect the atmosphere, hydrosphere, biosphere, and pedosphere (Mathew et al., 2018; Pal and Ziaul, 2017; Xystrakis et al., 2017; Yaşar Korkanç, 2018). The atmosphere-land energy exchange dominated by land surface energy balance significantly impacts the formation and evolution of regional environments and global climate change. Thus, land surface energy balance is the main topic of research on land surface processes. This energy balance directly influences the changes in land surface (soil) temperature. On the other hand, land surface temperature also exert significant effect on energy exchange at the landatmosphere interface (Burakowski et al., 2018; Wang et al., 2018). Hence, several 
large-scale field experiments on land surface processes consider land surface energy and temperature to be major observational items, such as EFEDA (Osann Jochum et al., 2006), NOPEX (Halldin et al., 1998), BOREAS (Sellers et al., 1995), and EBEX2000 (Oncley et al., 2007). Significant progress has been made in understanding the land surface energy balance and temperature for different land surfaces/ecosystems, including studies on plateaus (Luo et al., 2018; Zhang et al., 2014), mountains (Gualtieri, 2018; Wagner et al., 2014), deserts (Urqueta et al., 2018), and forests (Gage and Cooper, 2017). Moreover, many studies have found a problem with the unclosure of the energy balance, i.e., the available energy is found to be larger than the sum of the turbulent fluxes of sensible and latent heat measured in these land surfaces (Foken, 2008). This energy unclosure is mainly attributed to the energy storage in the upper soil layer and the heterogeneity of the land surface (Foken et al., 2006). Thus, these two reasons must be considered and corrected through studying the land surface processes, especially in the ecotone where vertical sensible heat advection may generate due to the heterogeneous land surface (Zhang et al., 2012a).

The oasis-desert ecotone that lies between the oases and deserts is an ecologically fragile zone (Tiyip et al., 2005), where characteristics of land surface energy balance strongly affect regional atmospheric circulation and surface temperature. In addition, there are some significant differences in the response of land surface energy balance with surface temperatures to different weather conditions. However, very few studies have focused on these aspects concerning oasis-desert ecotones thus far. Hence, investigating the land surface energy balance and its relationship with land surface temperature in this area can contribute to the research on regional surface energy balance and improve the regional weather and global climate model. It will also provide references for the optimal regulation of water resources in this region. The objectives of this study are: (1) to compare the characteristics of surface energy balance under different weather conditions; (2) to compare the patterns of surface energy partitioning with those of other nine land surfaces in the arid zone of Northwest China; and (3) to quantify the relationship between land surface temperature and energy component.

\section{Materials and methods}

\section{Study area}

The trial was conducted on the Achnatherum splendens grassland near the Wanmuchun forest-farm, Qitai County, Xinjiang Province, China. The area is $2 \mathrm{~km}$ southeast of the Gurbantunggut Desert in the northern piedmont of the East Tianshan Mountains. It represents a typical oasis-desert ecotone in northwest China (Fig. 1). The geographic location of the study site is $44^{\circ} 11^{\prime} 19^{\prime \prime} \mathrm{N}, 89^{\circ} 25^{\prime} 32^{\prime \prime} \mathrm{E}$, and the altitude is $693 \mathrm{~m}$ above sea level. The climate of the region is temperate continental and arid climate with an annual mean precipitation of only $150 \mathrm{~mm}$, whereas annual potential evaporation reaches above $2100 \mathrm{~mm}$. The average annual temperature is approximately $5{ }^{\circ} \mathrm{C}$, with 2933.6 annual sunshine hours.

The area of experimental zone is approximately 2100 ha $(3000 \mathrm{~m} \times 7000 \mathrm{~m})$. It is mainly covered with A. splendens, a perennial, densely tufted Gramineae, accompanied by sparse Sophora alopecuroides and Salsola collina Pall. The total coverage is roughly $30 \%$. The soil is sandy loam, and the groundwater depth range from 3 to $5 \mathrm{~m}$. 


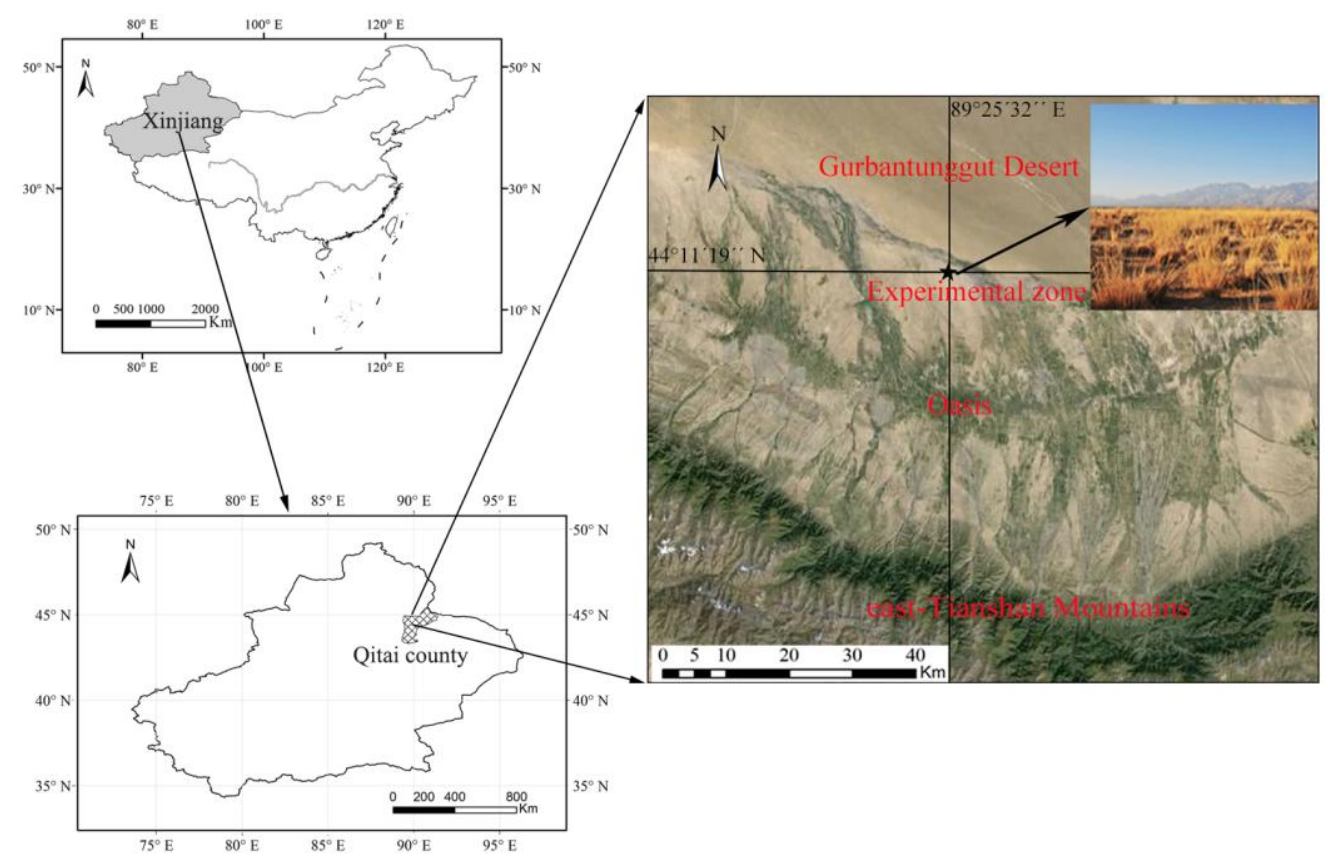

Figure 1. Location of the study area

\section{Bowen ratio/energy balance method and its modification}

The Bowen ratio/energy balance (BREB) method (Bowen, 1926) has been widely used to measure land surface energy. This method can provide accurate, continuous measurement of micrometeorological elements and energy balance components over an extensive surface area (Dugas and Mayeux Jr, 1991). The core concept of BREB method is to divide the available energy into turbulent sensible heat and latent heat fluxes by using the Bowen ratio (Uddin et al., 2013).

The energy balance of land surface, neglecting small amount of photosynthetic energy storage, can be expressed as:

$$
R n=L E+H+G
$$

where $R n$ is the net radiation $\left(\mathrm{W} / \mathrm{m}^{2}\right), L E$ the latent heat of evapotranspiration $\left(\mathrm{W} / \mathrm{m}^{2}\right)$, $H$ the sensible heat flux $\left(\mathrm{W} / \mathrm{m}^{2}\right)$, and $G$ the soil heat flux $\left(\mathrm{W} / \mathrm{m}^{2}\right) . R n$ and $G$ are obtained from the observation. Except in extremely unstable or stable atmospheric situation, The Bowen ration $(\beta)$ is defined as the ratio of sensible heat flux to the latent heat $(H / L E)$ (Bowen, 1926). Therefore, Equation 1 can be rewritten as (Eq. 2):

$$
L E=(R n-G) /(1+\beta)
$$

The Bowen ratio $(\beta)$ can be calculated as

$$
\beta=H / L E=\rho c_{p} K_{\mathrm{H}} \Delta t / \rho c_{p} K \mathrm{v} \Delta e=\gamma(\Delta t / \Delta e)
$$

where $\rho$ is air density, $c_{p}$ the specific heat of air at a constant pressure $\left(\mathrm{cal} \cdot \mathrm{g}^{-1} \cdot \mathrm{K}^{-1}\right) . K_{H}$ and $K_{V}$ are the turbulent transfer coefficients for heat and vapour, respectively. $\gamma$ is 
psychrometric constant, $\Delta t$ and $\Delta e$ the differences in the air temperature $\left({ }^{\circ} \mathrm{C}\right)$ and water vapor pressure $(\mathrm{hPa})$ between the two heights, respectively. In Equation 3, $K_{H}$ is assumed to be equal to $K_{V}$ for neutral to moderately unstable atmospheric condition over smooth terrain (Spittlehouse and Black, 1980). And this assumption is usually valid except in extremely unstable or stable atmospheric condition (Dugas and Mayeux Jr, 1991). For instance, $K_{H}$ is greater than $K_{V}$ for stable conditions.

Many previous studies assumed the $G$ to be the direct measured value of soil heat flux transducer at $0.05 \mathrm{~m}$ below the soil surface, but in reality $G$ also includes the heat stored in the 0 to $0.05 \mathrm{~m}$ layer computed from measurement of the change in temperature of the layer with time and the heat capacity of the layer. Thus its computation should be modified as (Eq. 4):

$$
G=G_{0.05}+C s \frac{\partial T}{\partial t} \Delta Z
$$

where $G_{0.05}$ denotes heat flux obtained from heat flux transducer at $0.05 \mathrm{~m}$ below the soil surface $\left(\mathrm{W} / \mathrm{m}^{2}\right), C_{S}$ the specific heat of dry soil $\left(\mathrm{J} \cdot \mathrm{kg}^{-1} \cdot{ }^{\circ} \mathrm{C}^{-1}\right), \frac{\partial T}{\partial t}$ is the rate of change in soil temperature over time, and $\Delta Z$ the depth of the soil layer measured, i.e., $0.05 \mathrm{~m}$.

Additionally, with respect to the flat and homogeneous surface, vertical sensible heat advection can be not taken into account due to its almost no occurrence. However, since there are some differences in surface thermodynamic properties between the oasis and the desert surface, sensible heat can be advected vertically to some extent in the inhomogeneous surfaces of ecotones, thereby generating vertical sensible heat advection $\left(H_{v a d}\right)$ (Zhang et al., 2012a, b). Thus, here the sensible heat $(\mathrm{H})$ comprises not only the turbulent sensible heat $\left(H_{0}\right)$ but also comprises the vertical sensible heat advection $\left(H_{v a d}\right)(E q .5)$ :

$$
H=H_{0}+H_{\text {vad }}
$$

where $H_{0}$ and $H_{\text {vad }}$ can be calculated as follows (Eqs. 6 and 7):

$$
\begin{gathered}
H_{0}=\beta L E \\
H_{v a d}=-\rho c_{\mathrm{p}} z r w_{r} \frac{\Delta T}{\Delta Z}
\end{gathered}
$$

where $\rho$ is air density; $c_{\mathrm{p}}$ is the specific heat capacity of air at a constant pressure $\left(\mathrm{cal} \cdot \mathrm{g}^{-1} \cdot \mathrm{K}^{-1}\right) ; w_{r}$ is the vertical wind speed of height $Z_{r}$; and $\Delta T / \Delta Z$ is the vertical gradient of temperature.

\section{Experimental design}

The Bowen ration system (Delta-T Devices Ltd., UK), similar to that used in (Peacock and Hess, 2004; Todd et al., 2000), was set up on the center of the experimental zone. Its main observed elements included net radiation, air temperature, air humidity, wind speed, soil temperature, soil moisture, the soil heat flux, and precipitation. Net radiation was measured at $0.5 \mathrm{~m}$ above the maximum height of the 
splendens canopy by a net radiometer. Sensors of air temperature and air humidity were installed in two layers, that is, $0.5 \mathrm{~m}$ and $2.5 \mathrm{~m}$ above the height of the canopy. Sensors of soil temperature and moisture were arranged in eight layers, that is, 0.05, 0.1, 0.15, $0.2,0.4,0.6,0.8$, and $1 \mathrm{~m}$ underground. The soil heat flux was measured with soil heat flux plate at $0.05 \mathrm{~m}$ below the soil surface. More details on each sensor are listed in Table 1, including sensitivity and estimation of errors. The diagrams of measurement configurations Bowen ratio system is seen in Figure 2. All observed data were automatically recorded at 30-min intervals by a data collector and then exported by a computer. Measurements were taken from 22 July to 3 September 2010. The distance between the site of instrument setup and the boundary of the experimental zone varied from $1510 \mathrm{~m}$ to $3534 \mathrm{~m}$, which meets the fetch requirement that the ratio of fetch (upwind distance of uniform conditions) to the height of the instrument above the surface needs to be greater 100 (Wiernga, 1993).

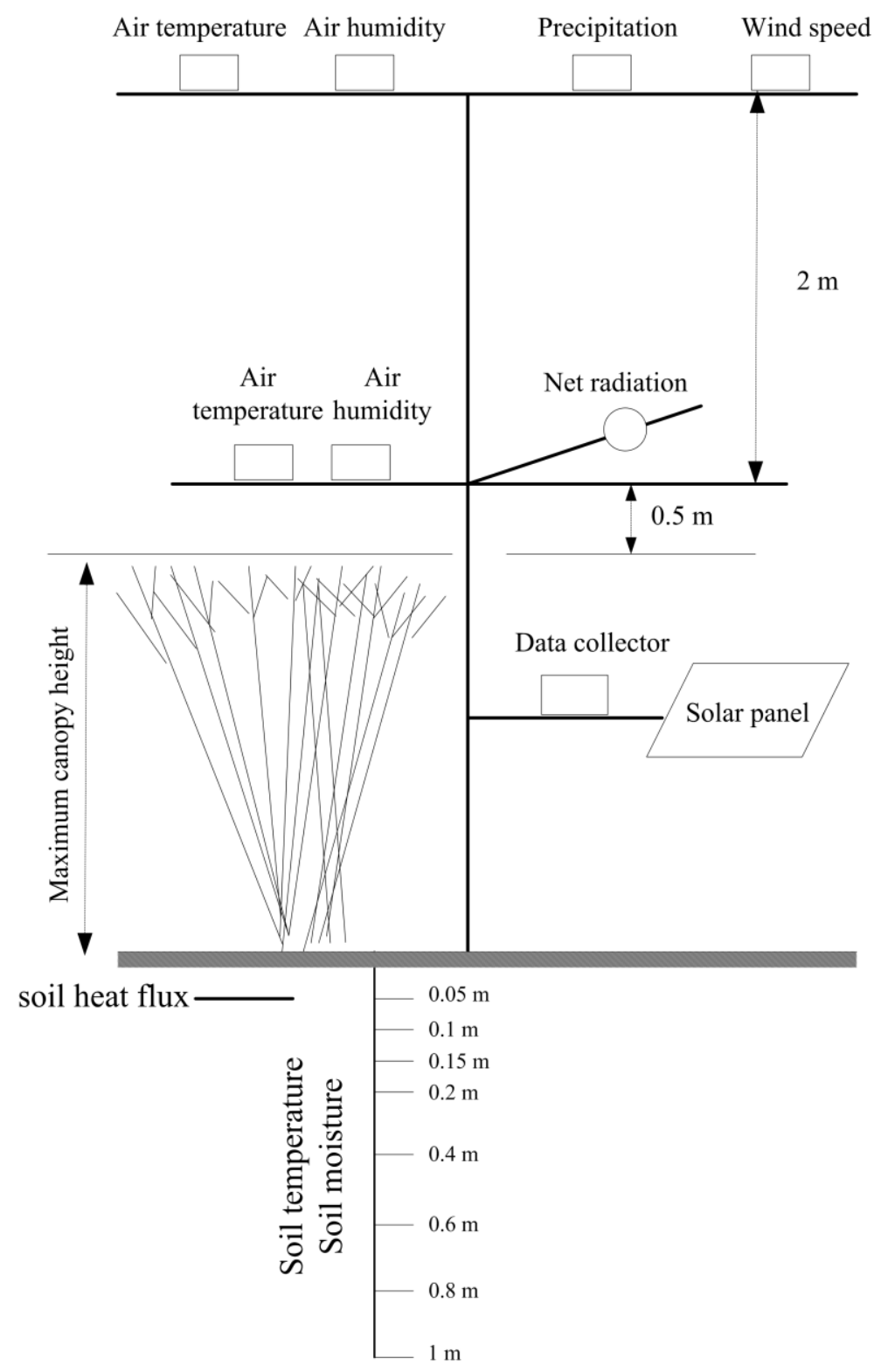

Figure 2. The scheme of Bowen ratio system 
Table 1. Details on each sensors of Bowen ratio system

\begin{tabular}{|c|c|c|c|c|}
\hline Sensor type & Observed item & Measurement range & Sensitivity & Accuracy \\
\hline NR2 & Net radiation & $-500 \sim 2000 \mathrm{~W} / \mathrm{m}^{2}$ & $0.09049-0.11210 \mathrm{mV} / \mathrm{W} / \mathrm{m}^{2}$ & $\pm 5 \%\left(20^{\circ} \mathrm{C}\right)$ \\
\hline RHT2 & Air humidity & $0-100 \%$ & $10 \mathrm{mV} / \% \mathrm{RH}$ & $\begin{array}{c} \pm 2 \%(5 \%<\mathrm{RH}<95 \%) \\
\pm 2.5 \%(\mathrm{RH}<5 \% \\
\mathrm{RH}>95 \%)\end{array}$ \\
\hline AT2 & Air temperature & $-20-80^{\circ} \mathrm{C}$ & $10 \mathrm{mV} /{ }^{\circ} \mathrm{C}$ & $\pm 0.5 \%\left(0.5^{\circ} \mathrm{C}\right)$ \\
\hline AN3 & Wind speed & $0.15-75 \mathrm{~m} / \mathrm{s}$ & $0.8 \mathrm{~Hz} / \mathrm{m} \cdot \mathrm{s}^{-1}$ & $\pm 0.1 \mathrm{~m} / \mathrm{s}$ \\
\hline TRIME-PICO-32 & Soil temperature & $-15-50^{\circ} \mathrm{C}$ & - & $\pm 0.2^{\circ} \mathrm{C}$ \\
\hline TRIME-PICO-64 & Soil moisture & $0-100 \%$ & - & $\begin{array}{c} \pm 1 \%(0<\mathrm{RH}<40 \%) \\
\pm 2 \%(40 \%<\mathrm{RH}<70 \%)\end{array}$ \\
\hline HFP01 & Soil heat flux & $-2000-2000 \mathrm{~W} / \mathrm{m}^{2}$ & $63.6 \mu \mathrm{V} / \mathrm{W} / \mathrm{m}^{2}$ & $\pm 5 \%$ \\
\hline RE1 & Precipitation & $0-500 \mathrm{~mm} / \mathrm{h}$ & - & $\pm 0.2 \mathrm{~mm} / \mathrm{h}$ \\
\hline
\end{tabular}

In addition, in order to analyze the effect of different land surfaces types on energy partitioning, we collected observation data of nine other stations with different surfaces types in the same arid zone of Northwest China, which were mainly obtained from previous published papers (Fig. 3). These stations are classified into three groups, namely, Desert/Gobi, Oasis-desert ecotone, and Oasis. Table 2 lists their geographic information, land surfaces types, and climatic backgrounds.

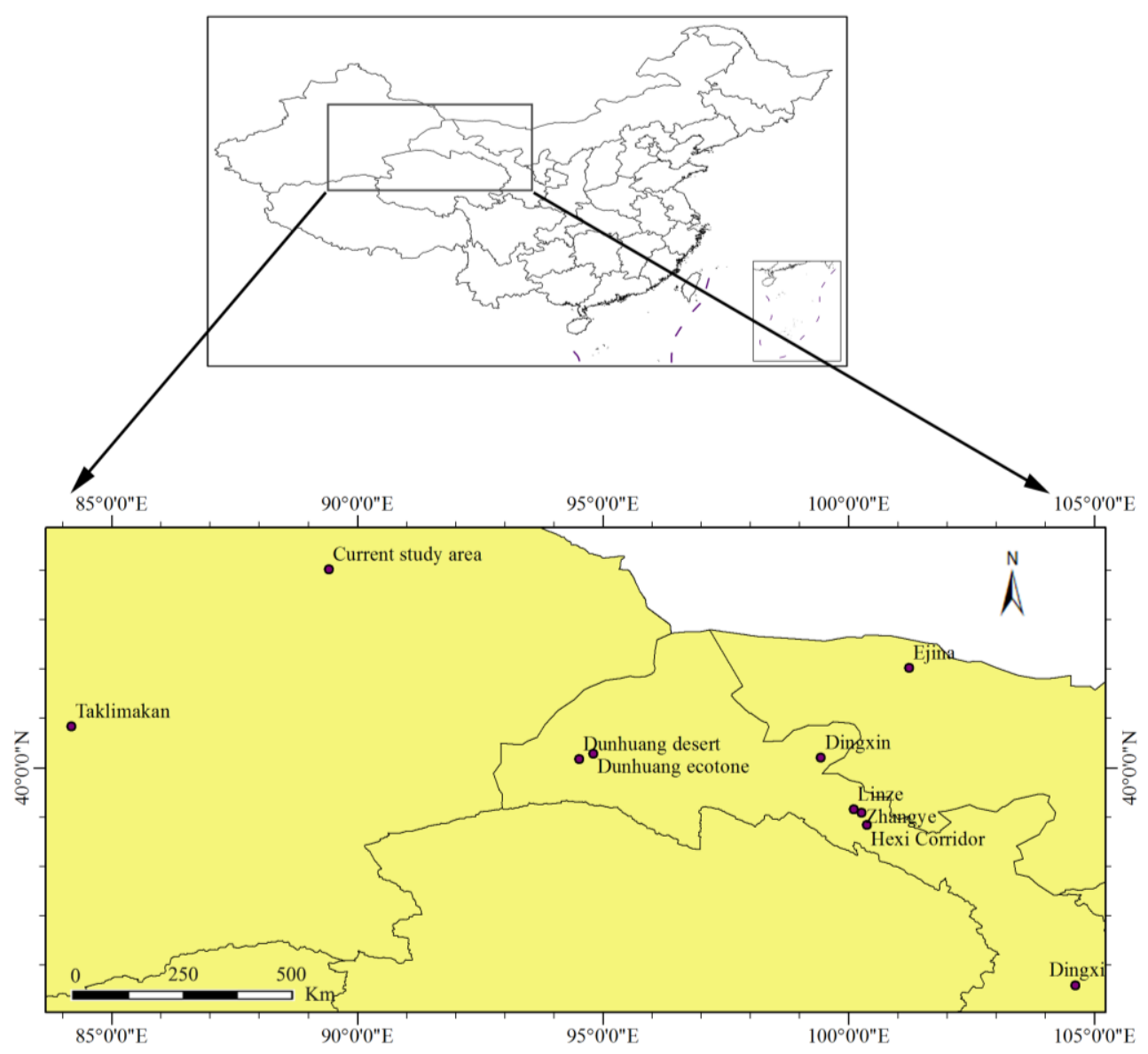

Figure 3. Location of ten selective observation stations in the arid zone of Northwest China 
Table 2. Stations' geographic information and climatic backgrounds in Northwest China

\begin{tabular}{|c|c|c|c|c|c|c|c|c|c|c|}
\hline $\begin{array}{c}\text { Land } \\
\text { surfaces }\end{array}$ & Station & $\begin{array}{l}\text { Latitude/ } \\
\text { Longitude }\end{array}$ & $\begin{array}{c}\text { Altitude } \\
\text { (m) }\end{array}$ & Land cover & $\begin{array}{c}\text { Precipitation } \\
(\mathrm{mm} / \mathbf{y r})\end{array}$ & \begin{tabular}{|c|} 
Annual \\
average \\
temperature \\
$\left({ }^{\circ} \mathrm{C}\right)$ \\
\end{tabular} & $\begin{array}{c}\text { Clear } \\
\text { day }\end{array}$ & $\begin{array}{c}\text { Overcast } \\
\text { day }\end{array}$ & $\begin{array}{c}\text { Rainy } \\
\text { day }\end{array}$ & Average \\
\hline \multirow{4}{*}{ Desert/Gobi } & Dunhuang $^{\mathrm{a}}$ & $\begin{array}{l}40^{\circ} 10^{\prime} \mathrm{N} / \\
94^{\circ} 31^{\prime} \mathrm{E}\end{array}$ & 1150 & Desert & 39 & 9.4 & $\sqrt{ }$ & $\sqrt{ }$ & $\sqrt{ }$ & $\sqrt{ }$ \\
\hline & Taklimakan ${ }^{\mathrm{b}}$ & $\begin{array}{l}40^{\circ} 48^{\prime} \mathrm{N} / \\
84^{\circ} 18^{\prime} \mathrm{E}\end{array}$ & 912 & Desert & 100 & 11.5 & $\sqrt{ }$ & $\sqrt{ }$ & & $\sqrt{ }$ \\
\hline & $\operatorname{Dingxin}^{c}$ & $\begin{array}{l}40^{\circ} 12^{\prime} \mathrm{N} / \\
99^{\circ} 26^{\prime} \mathrm{E}\end{array}$ & 1192 & Bare land & 65 & 8.6 & $\sqrt{ }$ & $\sqrt{ }$ & $\sqrt{ }$ & $\sqrt{ }$ \\
\hline & $\operatorname{Linze}^{\mathrm{d}}$ & $\begin{array}{l}39^{\circ} 09^{\prime} \mathrm{N} / \\
100^{\circ} 06^{\prime} \mathrm{E}\end{array}$ & 1480 & Desert & 95 & 7.6 & & & & $\sqrt{ }$ \\
\hline \multirow{4}{*}{$\begin{array}{c}\text { Oasis- } \\
\text { desert } \\
\text { ecotone/ } \\
\text { Oasis-gobi } \\
\text { ecotone }\end{array}$} & Zhangye $^{\mathrm{e}}$ & $\begin{array}{l}39^{\circ} 05^{\prime} \mathrm{N} / \\
100^{\circ} 16^{\prime} \mathrm{E}\end{array}$ & 1480 & Sparse grassland & 107 & 7.8 & $\sqrt{ }$ & & & \\
\hline & Ejina $^{\mathrm{f}}$ & $\begin{array}{l}42^{\circ} 01^{\prime} \mathrm{N} / \\
101^{\circ} 14^{\prime} \mathrm{E}\end{array}$ & 927 & $\begin{array}{c}\text { Phragmites } \\
\text { grassland }\end{array}$ & 38 & 8.2 & & & & $\sqrt{ }$ \\
\hline & Dunhuang $^{\mathrm{g}}$ & $\begin{array}{l}40^{\circ} 30^{\prime} \mathrm{N} / \\
94^{\circ} 75^{\prime} \mathrm{E}\end{array}$ & 1090 & $\begin{array}{c}\text { Sparse sparsifolia } \\
\text { grassland/Bare } \\
\text { land }\end{array}$ & 40 & 8.9 & $\sqrt{ }$ & & & \\
\hline & $\begin{array}{c}\text { Current } \\
\text { study area }\end{array}$ & $\begin{array}{l}44^{\circ} 01^{\prime} \mathrm{N} / \\
89^{\circ} 25^{\prime} \mathrm{E}\end{array}$ & 693 & $\begin{array}{l}\text { Splendens } \\
\text { grassland }\end{array}$ & 150 & 5.5 & $\sqrt{ }$ & $\sqrt{ }$ & $\sqrt{ }$ & $\sqrt{ }$ \\
\hline \multirow{2}{*}{ Oasis } & Dingxi ${ }^{\mathrm{h}}$ & $\begin{array}{l}35^{\circ} 35^{\prime} \mathrm{N} / \\
104^{\circ} 37^{\prime} \mathrm{E}\end{array}$ & 1897 & $\begin{array}{l}\text { Non-irrigated } \\
\text { farmland }\end{array}$ & 386 & 6.7 & $\sqrt{ }$ & $\sqrt{ }$ & & $\sqrt{ }$ \\
\hline & $\begin{array}{c}\text { Hexi } \\
\text { Corridor }^{\mathrm{i}}\end{array}$ & $\begin{array}{l}38^{\circ} 50^{\prime} \mathrm{N} / \\
100^{\circ} 22^{\prime} \mathrm{E}\end{array}$ & 1565 & Irrigated farmland & 100 & 7.6 & & & & $\sqrt{ }$ \\
\hline
\end{tabular}

'Zhang and Cao (2003); ${ }^{\mathrm{b}}$ Wang et al. (2014); ${ }^{\mathrm{c}} \mathrm{W}$ ang et al. (2008); ${ }^{\mathrm{d}}$ Zheng et al. (2000); ${ }^{\mathrm{e}}$ Zhang et al. (2007); ${ }^{\text {S }}$ i et al. (2010); ${ }^{\mathrm{g}} \mathrm{W}$ ang et al. (2005); ${ }^{\mathrm{h}}$ Yang et al. (2004); ${ }^{\mathrm{i}}$ Zheng et al. (2000)

$\sqrt{ }$ in the body of table indicates that the observation data is available

\section{Examining relationship between land surface energy and temperatures}

In order to investigate the relationship between soil temperature and surface energy accurately, a Pearson correlation coefficient (Pearson, 1895) and linear regression (Weisberg, 1985) method were used to quantify the relationship between land surface energy and temperatures. More detailed information about the methods can be found in Pearson (1895) and Weisberg (1985)

\section{Results and discussion}

\section{Daily variation in land surface energy}

In order to analyze the effects of different weather conditions on the land surface energy, 14 typical clear days (total cloud cover $<1$ okta), 5 overcast days (total cloud cover $>7 \mathrm{okta})$, and 2 rainy days $(1.2 \mathrm{~mm} / \mathrm{h}, 3-7 \mathrm{okta})$ are derived from the observation period as sample data. Then, the daily variation in land surface energy at half-hour scales for different weather conditions are shown in Figures 2-5. These curves are generated according to the average of the sample data with similar weather conditions.

\section{Clear days}

On clear days, all of the surface energy components $(R n, L E, H$, and $G)$ display a single peak with a clear day-night difference (Figure 4). Although the general pattern of $L E$ change is the same as that of $R n$ change, its daily maximum is half an hour later than that of $R n$. $L E$ become negative after sunset because of the water vapor exchange 
between soil and atmosphere over a desert surface near an oasis in the summer. After midnight, it shifted to a low positive, thus implying that slight evapotranspiration still occur. $H$ is positive in the daytime and negative at night, which suggests that the $H$ flux moves from the land surface to the atmosphere in the daytime, while it moves from atmosphere to land surface at night. The range of the daily variation in $G$ is only approximately $80 \mathrm{~W} / \mathrm{m}^{2}$, and its daily maximum is more than two hours later than that of $R n$. When the value of $G$ is greater than 0 in the daytime, the soil absorbed heat as a heat sink. By contrast, the soil releases heat as a heat source when the value of $G$ is less than 0 at night.

The total daily values on clear day of $R n, L E, H$, and $G$ are $13.53 \times 10^{6}, 9.41 \times 10^{6}$, $3.91 \times 10^{6}$, and $0.27 \times 10^{6} \mathrm{~J} / \mathrm{m}^{2}$, respectively. This finding indicates that $L E$, rather than $H$, is dominant in terms of surface energy budget (accounting for $70 \%$ of $R n$ ) on clear days. This is significantly different from the other arid regions in northwest China under the same weather condition. For instances, the value of $L E$ is lower than that of $H$ in Zhangye oasis-desert ecotone (Zhang et al., 2007) and Dunhuang oasis-gobi ecotone (Wang et al., 2005) over the same period (Table 3). This result can be attributed to the fact that the vegetation coverage index of the Zhangye oasis-desert ecotone is only $37 \%$ of that of the current study area. Furthermore, the Dunhuang oasis-gobi ecotone is mainly covered with Alhagi sparsifolia, where PAI (plant area index, which is the sum of the leaf area index and the woody area index) and annual precipitation is low. Thus, $L E$ induced by plant transpiration is lower in the Zhangye and Dunhuang ecotone than that in the current study area. Likewise, $H$ is dominant in the Dunhuang Desert (Zhang and Cao, 2003), Taklimakan Desert (Wang et al., 2014), and Dingxin Gobi (Wang et al., 2008) because of sparse vegetation and bare soil (Table 2). Although $L E$ is dominant in the non-irrigated farmland of Dingxi Oasis (Yang et al., 2004), its proportion is smaller than that of the current study area. This is because farmland is converted into bare land, after reaping wheat in mid-August. These comparisons showed that different vegetation cover conditions significantly affect the surface energy partitioning.

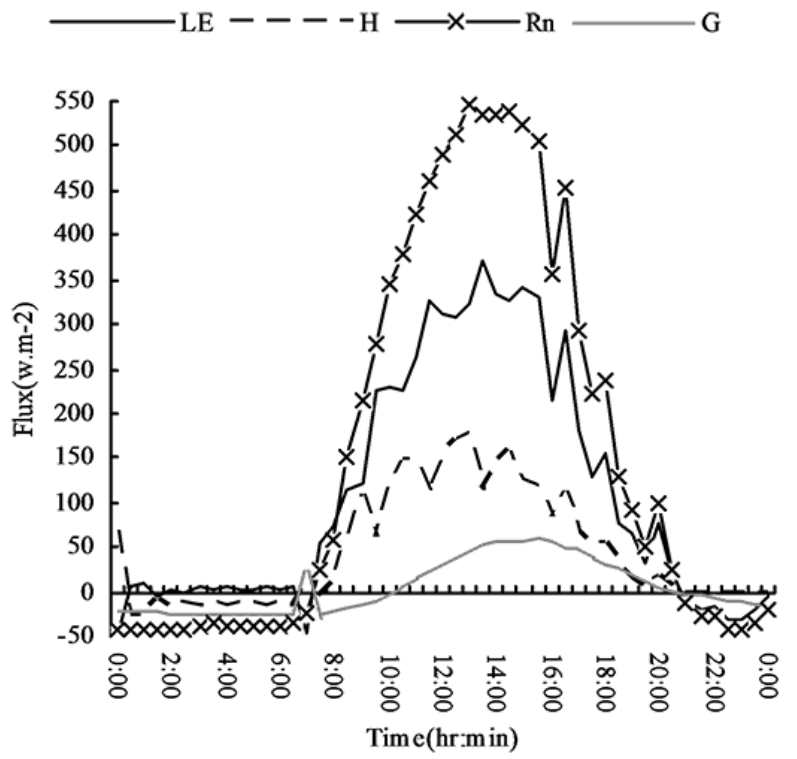

Figure 4. Daily variations in surface energy balance on clear days in splendens grassland. LE is the latent heat of evapotranspiration, $H$ the sensible heat flux, $R n$ the net radiation, and $G$ the soil heat flux 
Table 3. LE/Rn and H/Rn of different land surfaces on clear and overcast summer days

\begin{tabular}{|c|c|c|c|c|}
\hline \multirow{2}{*}{ Types of underlying surfaces } & \multicolumn{2}{|c|}{ Clear day } & \multicolumn{2}{|c|}{ Overcast day } \\
\hline & $L E / R n$ & $H / R n$ & $L E / R n$ & $H / R n$ \\
\hline Current study area & $69.58 \%$ & $28.94 \%$ & $130.80 \%$ & $21.37 \%$ \\
\hline Dunhuang Desert $^{\mathrm{a}}$ & $1.64 \%{ }^{\mathrm{a}}$ & $83.60 \%{ }^{\mathrm{a}}$ & $2.73 \%^{\mathrm{a}}$ & $155.60 \%{ }^{\mathrm{a}}$ \\
\hline Taklimakan Desert ${ }^{\mathrm{b}}$ & $21.62 \%{ }^{b}$ & $72.97 \% \mathrm{~b}$ & $12.83 \%^{\mathrm{b}}$ & $92.10 \%{ }^{\mathrm{b}}$ \\
\hline Dingxin Gobi ${ }^{\mathrm{c}}$ & $8.10 \%{ }^{\mathrm{c}}$ & $86.80 \%^{\mathrm{c}}$ & $-6.30 \%{ }^{\mathrm{c}}$ & $102.20 \%^{\mathrm{c}}$ \\
\hline Dunhuang oasis-gobi ecotone $^{\mathrm{d}}$ & $18.69 \% \mathrm{~d}$ & $76.87 \%{ }^{\mathrm{d}}$ & -- & -- \\
\hline Zhangye oasis-desert ecotone $\mathrm{e}^{\mathrm{e}}$ & $9.84 \%{ }^{\mathrm{e}}$ & $66.57 \%{ }^{\mathrm{e}}$ & -- & -- \\
\hline Dingxi Oasis ${ }^{\mathrm{f}}$ & $54.97 \%{ }^{\mathrm{f}}$ & $29.13 \%{ }^{\mathrm{f}}$ & $57.65 \%{ }^{\mathrm{f}}$ & $27.16 \%{ }^{\mathrm{f}}$ \\
\hline
\end{tabular}

${ }^{\mathrm{a}}$ Zhang and Cao (2003); ${ }^{\mathrm{b}}$ Wang et al. (2014); ${ }^{\mathrm{c}} \mathrm{Wang}$ et al. (2008); ${ }^{\mathrm{d}} \mathrm{W}$ ang et al. (2005); ${ }^{\mathrm{e}}$ Zhang et al. (2007); ' Yang et al. (2004)

-- in the body of table indicates that the observation data is not available

\section{Overcast days}

On overcast days, energy curves affected by fluctuating cloudiness are divided into multiple peaks and troughs (Figure 5). The highest peaks of $R n, L E$, and $H$ are lowered to $46 \%, 40 \%$, and $45 \%$ of the corresponding values on sunny days, respectively. With the exception of the period from 12:00 to 13:30, the value of $G$ is less than 0 throughout the day, thus indicating that soil mainly releases heat into the atmosphere as a heat source to compensate for the insufficient $R n$ on overcast days.

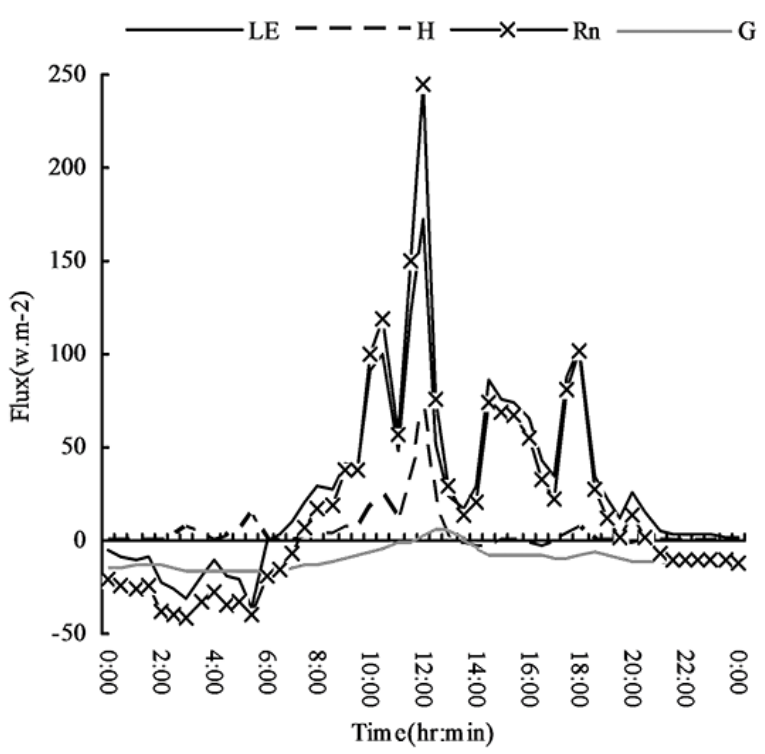

Figure 5. Daily variations in surface energy balance on overcast days in splendens grassland. $L E$ is the latent heat of evapotranspiration, $H$ the sensible heat flux, $R n$ the net radiation, and $G$ the soil heat flux

The total daily values on overcast day of $L E, H$, and $G$ are $2.32 \times 10^{6}, 0.38 \times 10^{6}$, and $-0.92 \times 10^{6} \mathrm{~J} / \mathrm{m}^{2}$. These values account for $130.80 \%, 21.37 \%$, and $-52.16 \%$ of $R n$, respectively. The reason why $L E / R n>1$ and $G / R n<0$ is that the soil continually releases heat to the atmosphere to replenish the inadequate energy for evaporation. 
Therefore, the value of $L E$ which also includes the additional heat derived from soil, is higher than $R n$. This phenomenon is specific for the splendens grassland and not the Dunhuang Desert, Taklimakan Desert, Dingxin Gobi, and Dingxi Oasis (Table 3). That may be explained by the differences in the soil property and vegetation cover among them. Although the value of $R n$ decreased, the large heat storage capacity of splendens grassland soil can provide sufficient energy for evapotranspiration on overcast days. As a result, $L E>R n$ and $G<0$. This finding demonstrates that splendens grassland soil stores heat on clear days, and then releases it on overcast days, that is, it has a cache energy function.

\section{Rainy days}

On rainy days, moderate amounts of rain fell early in the morning and stopped at noon. The weather then turned fine. As a result of precipitation, the time-point of each energy balance component begins to increase rapidly is more than four hours later than that on sunny days (Figure 6). This lag contributes to the "lagged peak" of each energy curve. The maxima of $R n$ and $H$ are $117 \%$ and $214 \%$ of those generated during sunny days, respectively. This result shows that the few clouds and low air turbidity might enhance the energy exchange between atmosphere and land when the sun shines again once the rain ceases. The peak value of $L E$ is similar to that on sunny days. This finding implies that grassland evapotranspiration rate remains high due to the increased available water and increased $R n$ on rainy days. $G$ remains negative during rainfall, that is, the soil releases heat to the atmosphere. Once the rain stopped, $G$ reaches the minimum value, i.e., the soil releases more energy to the atmosphere and promotes the appearance of the $L E$ peak.

The total daily values of $L E, H$, and $G$ on rainy day are $6.35 \times 10^{6}, 3.49 \times 10^{6}$, and $-6.35 \times 10^{5} \mathrm{~J} / \mathrm{m}^{2}$, respectively. These values are responsible for $68.96 \%, 37.94 \%$, and $-6.90 \%$ of $R n$, respectively. This finding indicates that $L E$ is dominant in rainy days. That is consistent with the results of Dingxin Gobi and Dunhuang Desert, where $L E$ is also dominant because of rainfall.

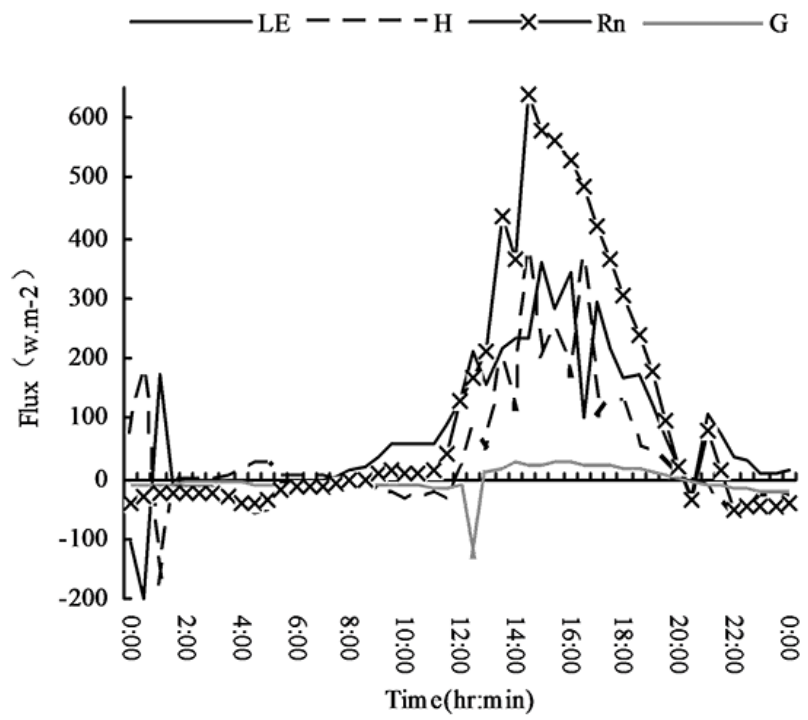

Figure 6. Daily variations in surface energy balance on rainy days in splendens grassland. LE is the latent heat of evapotranspiration, $H$ the sensible heat flux, Rn the net radiation, and $G$ the soil heat flux 


\section{Average}

The average values of each energy components (calculated from the average of all observed data during the observation period) decrease compared to those of clear days. Nonetheless, the general trends of the daily variation curves are consistent with those observed on clear days (Figure 7). The average value of $L E / R n(59 \%)$ is significantly higher than that observed in the Linze Desert (Zheng et al., 2000), Dunhuang Desert, Taklimakan Desert, and Dingxin Gobi over the same period. However, this value is lower than that obtained in the irrigated farmland of the Hexi Corridor Oasis (Zheng et al., 2000; Table 4). As a result of the dry climate and sparse vegetation, the reduced capability of holding and retaining water leads to the severe scarcity of water for evapotranspiration in the first four ecosystems. Nevertheless, in the irrigated farmland of the Hexi Corridor Oasis, the high water content of the soil and vegetation due to the high vegetation coverage and artificial irrigation induces vigorous evapotranspiration. Therefore, $L E$ plays a predominant role in the energy exchange, whose proportion is $9.2 \%$ larger than that observed in the current study area. The current study area's transition property in the energy partitioning might be attributed to the thermalhydrologic property between deserts and oases and the local circulation. The differences in the thermal property between the oasis and the desert cause the local circulation. Then the horizontal advection caused by local circulation transfers the hot and dry air from the desert to the oasis-desert ecotone. Consequently, the temperature gradient decreases and the humidity gradient increases that leads to a reduction in $H$ and increase in $L E$ so that $L E$ become predominant in the surface energy budget of ecotone. Moreover, the value of $L E / R n$ is slightly higher than that of the Ejina oasis-desert ecotone (Si et al., 2010) because the annual precipitation in the Ejina oasis-desert is only one quarter of that in the current study area. This suggests that surface energy balance is not entirely controlled by vegetation cover, and climatic conditions may be also important.

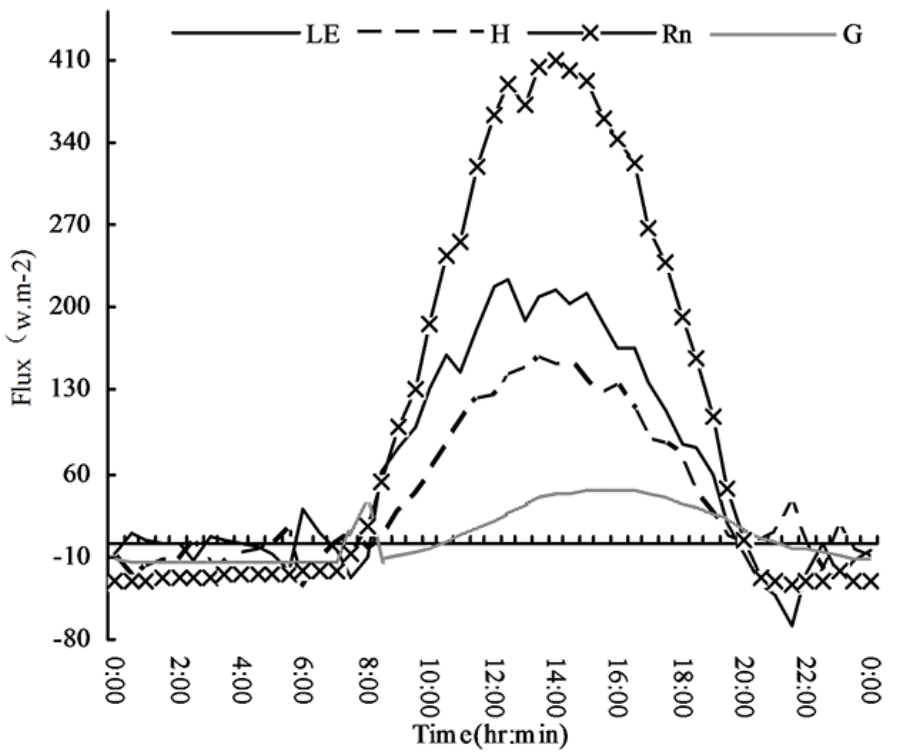

Figure 7. Daily variations in surface energy balance under the average condition in the splendens grassland. LE is the latent heat of evapotranspiration, H the sensible heat flux, Rn the net radiation, and $G$ the soil heat flux 
Table 4. LE/Rn and H/Rn values of different land surfaces under the average condition in summer

\begin{tabular}{c|c|c}
\hline Types of underlying surfaces & $\boldsymbol{L E} / \boldsymbol{R} \boldsymbol{n}$ & $\boldsymbol{H} / \boldsymbol{R} \boldsymbol{n}$ \\
\hline Current study area $^{\text {Dunhuang Desert }}{ }^{\mathrm{a}}$ & $58.8 \%$ & $37.1 \%$ \\
Linze Desert $^{\mathrm{b}}$ & $3.80 \%^{\mathrm{a}}$ & $86 \%^{\mathrm{a}}$ \\
Taklimakan Desert $^{\mathrm{c}}$ & $6.70 \%^{\mathrm{b}}$ & $88 \%^{\mathrm{b}}$ \\
Dingxin Gobi $^{\mathrm{b}}$ & $4.5 \%^{\mathrm{c}}$ & $52.5 \%^{\mathrm{c}}$ \\
Ejina oasis-desert ecotone $^{\mathrm{e}}$ & $5.2 \%^{\mathrm{d}}$ & $87 \%^{\mathrm{d}}$ \\
Dingxi Oasis $^{\mathrm{f}}$ & $49.6 \%^{\mathrm{e}}$ & $46.2 \%^{\mathrm{e}}$ \\
Hexi Corridor Oasis $^{\mathrm{g}}$ & $55.5^{\mathrm{f}}$ & $42.9^{\mathrm{f}}$ \\
\hline
\end{tabular}

${ }^{\mathrm{a}}$ Zhang and Cao (2003); ${ }^{\mathrm{b}}$ Wang et al. (2005); ${ }^{\mathrm{C}}$ Wang et al. (2014); ${ }^{\mathrm{d}}$ Wang et al. (2008); ${ }^{\mathrm{e}} \mathrm{Si}$ et al. (2010);

${ }^{\mathrm{f}}$ Yang et al. (2004); ${ }^{\mathrm{g}}$ Zheng et al. (2000)

\section{Daily variation in energy partitioning}

Figure 8 shows the daily variations in energy partitioning for different weather conditions. The general pattern in the daytime variation of energy partitioning is similar among the four different weather conditions. The available surface energy is primarily transformed into $L E$, as indicated in the order $L E / R n>H / R n>G / R n$. However, before midnight (20:30-24:00), $L E / R n>G / R n>H / R n$ is observed for clear days and the average condition, thus suggesting that a certain amount of evapotranspiration still occur (Fig. $8 a$ and $d$ ). By contrast, $H / R n$ is highest on overcast and rainy days at the same time (Fig. $8 b$ and $c$ ). After midnight (24:00-8:00 the next day), $G$ is dominant in the energy balance for all different weather conditions except rainy days. It implies that the soil becomes the main heat source of the soil-plant-atmosphere continuum (SPAC) system in the grassland after midnight.

In the daytime, the curves of $G / R n, H / R n$, and $L E / R n$ have not significant change for each weather condition (Fig. 8). However, at night, these curves fluctuated continuously. At sunrise and sunset, with the conversion of the heat source between the atmosphere and the soil (from soil to atmosphere or from atmosphere to soil), the changes in the direction of energy transport and energy intensity trigger the severe oscillation of curves, thus resulting in large peaks or troughs. The range of fluctuation in $L E / R n$ is the widest among all of the curves at sunrise. The result might be because following night condensation, much dew available for evapotranspiration is generated on the soil surface and the vegetation surface at sunrise. Although the value of $R n$ changes from negative to a relatively low positive, this value is far lower than that of $G$ (whose direction is negative). Thus, at this point, the value of $L E$ is almost equal to the sum of $R n$ and $G$. As a result, $L E / R n$ is greater than 1 (on rainy days, this value is close to 10 ), thereby mutating $L E / R n$ significantly. It also explains why the trend of change in the curve of $L E / R n$ is opposite to that of $G / R n$ in the peak. The time-points at which all of the curves change substantially in the mornings and evenings of overcast days are half an hour later and half an hour earlier, respectively, than those under the average condition because of the decreased solar radiation and reduced sunshine hours. On sunny days, the time-points are half an hour earlier and four hours later than those under the average condition because of the strong radiation and long sunshine hours. On rainy 
days, the time-points at which all energy curves deviate to the right are one and a half hours later than that under the average condition.
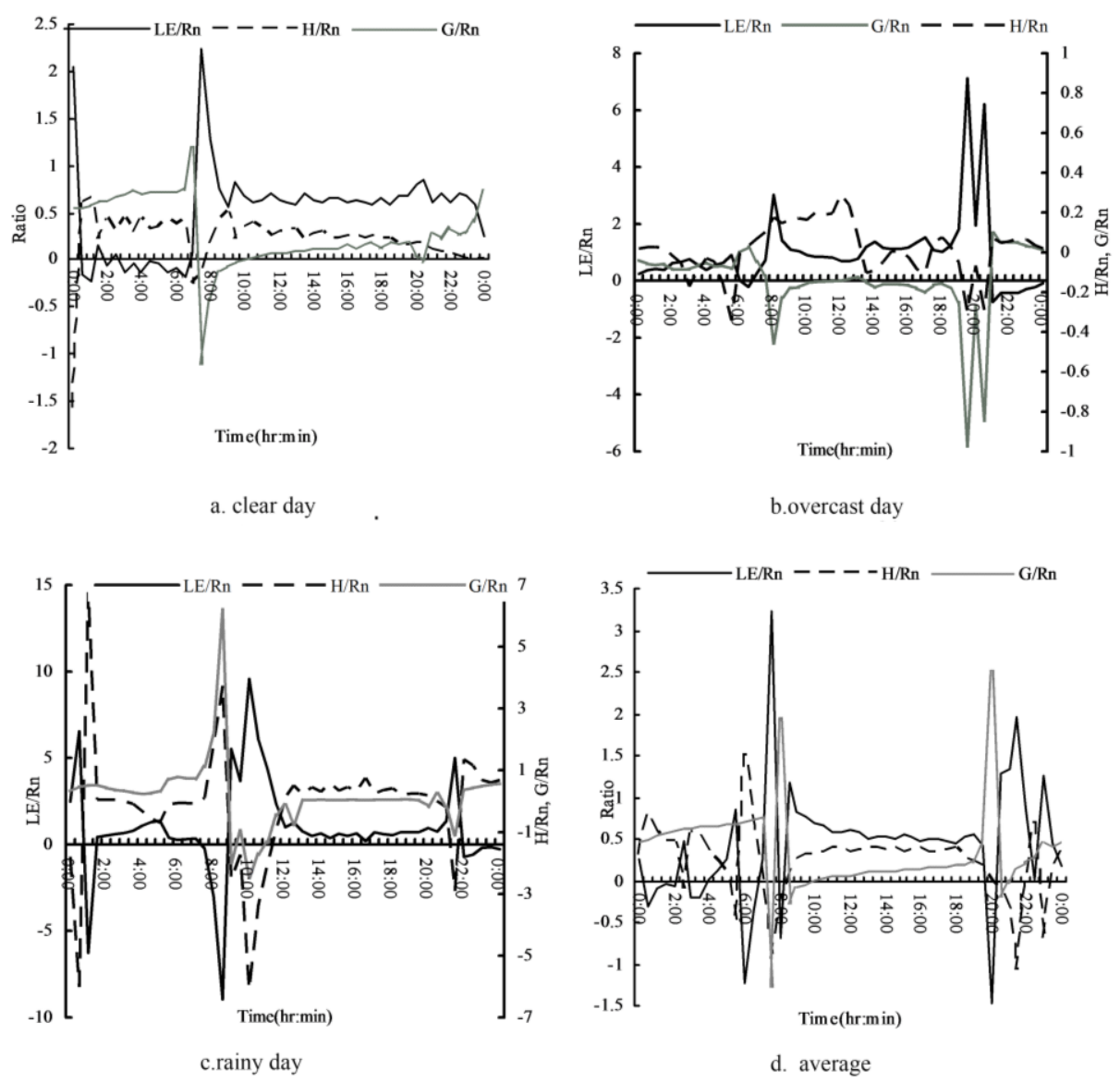

Figure 8. Daily variations in energy partitioning under different weather conditions. LE is the latent heat of evapotranspiration, $H$ the sensible heat flux, Rn the net radiation, and $G$ the soil heat flux

\section{Relationship between land surface energy and surface temperature}

\section{Correlations between land surface energy and soil temperature at different depths}

In order to investigate the relationship between soil temperature and surface energy accurately, this study stratified soil into four layers measuring, namely, 5, 10, 15, and 20 $\mathrm{cm}$. Since surface energy exchange mainly occurs during the daytime, only the results during daytime (8:00-18:00) over the observation period are analyzed here (Table 5). Moreover, their significance level is also tested.

The correlation between each energy component and soil temperature decreases gradually and is increasingly negatively correlated, with increasing soil depth (Table 5). This finding is due to the gradual delay in the peak time of soil temperature with the increase in depth, which enhanced the non-synchronism between the soil temperature and land surface energy. At $20 \mathrm{~cm}$, the trend of soil temperature is opposite to that of land surface energy; therefore, the correlation between both is predominantly negative. Among the layers, the soil temperature at $5 \mathrm{~cm}$ displays the best correlation with energy components. For instance, the coefficient between the soil temperature at $5 \mathrm{~cm}$ and $G$ is 
$0.61,5.81,1.72$, and 0.54 times larger than those at 10,15 , and $20 \mathrm{~cm}$ on average, respectively. This result is ascribed to the fact that the energy exchange firstly begins in the topsoil which is the critical plane of the SPAC system. Therefore, only the relationship between the soil temperature at $5 \mathrm{~cm}$ and energy components is analyzed as presented in the following section.

Table 5. Correlation coefficients between the energy components and soil temperature. ** represents $p<0.01$, denoting the correlation between the two corresponding variables is statistically highly significant

\begin{tabular}{c|c|c|c|c}
\hline & $\boldsymbol{R n}$ & $\boldsymbol{G}$ & $\boldsymbol{L}$ & $\boldsymbol{H}$ \\
\hline $\mathrm{T}_{\text {soil-5cm }}$ & $0.4234^{* *}$ & $0.8754^{* *}$ & $0.2328^{* *}$ & $0.2804^{* *}$ \\
$\mathrm{~T}_{\text {soil-10cm }}$ & $0.0556^{* *}$ & $0.5426^{* *}$ & -0.0145 & -0.0337 \\
$\mathrm{~T}_{\text {soil-15cm }}$ & $-0.2289^{* *}$ & $0.1286^{* *}$ & $-0.1733^{* *}$ & $-0.2675^{* *}$ \\
$\mathrm{~T}_{\text {soil-20cm }}$ & $-0.3653^{* *}$ & $-0.3215^{* *}$ & $-0.1955^{* *}$ & $-0.3667^{* *}$ \\
$\mathrm{~T}_{\text {soil-average }}$ & $0.1410^{* *}$ & $0.5695^{* *}$ & $0.0707^{* *}$ & $0.0241^{* *}$ \\
\hline
\end{tabular}

The correlations between each energy component $(R n, L E, H$, and $G)$ and soil temperature are all significant; however, that of $G$ and soil temperature is the best. The correlations of $R n$ and $H$ with soil temperature are intermediate, while the correlation of $L E$ with soil temperature is the least significant (Table 5). This finding is mainly resulted from the fact that $G$ has the most direct effect on the change in soil temperature compared to other energy components, because it represents the amount of heat passing in and out of the soil. For instance, when the value of $G$ is positive and high, the heat flow transferred continuously from the land surface to soil layers, thus accumulating soil energy and increasing soil temperature. However, $R n, L E$, and $H$ exerted their indirect effects on the soil temperature by means of $G$. These results demonstrate that soil temperature is more sensitive to $G$ than to other energy components.

\section{Relationship between land surface energy and soil temperature under different weather conditions}

$G$ is most closely related to soil temperature under sunny conditions, followed by its correlations under overcast and rainy conditions (Table 6). On overcast days, the negative correlation between the amount of clouds and soil temperature on overcast days weakens the relationship between $G$ and soil temperature. In addition, $R n$ and air temperature decrease on overcast days because of clouds. Thus, $G$ lessens and soil temperature changes very slowly. Finally, the correlation coefficient $\left(\mathrm{R}^{2}\right)$ between $G$ and soil temperature is only $81 \%$ of what it is on sunny days (Table $6 b$ ). On rainy days, a significant cooling effect of precipitation on soil temperature contributes to a negative correlation between precipitation and soil temperature. It interferes with the synchronism of $G$ and soil temperature. Thus, the coefficient on rainy days is equivalent to only $50 \%$ of that on sunny days (Table $6 c$ ). Since there are less overcast and rainy days during the observation period, the value of the coefficient under the average condition is similar to that on sunny days (approximately 0.61) (Table 6d). The response sensitivity (linear regression coefficient) of soil temperature to change in $G$ indicates that the values observed during sunny days are equivalent to those generated under the 
average condition, followed by those observed on overcast days. Those observed on rainy days are the lowest.

Similar to $G$, the linear correlations between $R n, L E$, and soil temperature among different conditions are ordered as follows: sunny days $>$ average condition $>$ overcast days $>$ rainy days. On sunny days, the soil temperature change substantially because of the increased $R n$ and $L E$. Therefore, soil temperature is mostly close to $R n$ and $L E$ on sunny day compared to that under other weather condition. On overcast and rainy days, the correlations observed are weakened because of the the interference of clouds and precipitation on these energy components.

The linear correlations between $H$ and soil temperature under different conditions are arranged as follows: average condition > rainy days $>$ sunny days $>$ overcast days. The response sensitivity (linear regression coefficients) of soil temperature to change in $H$ demonstrates that average condition $>$ sunny days $>$ rainy days $>$ overcast days.

Table 6. Relationship between land surface energy and soil temperature $\left(T_{\text {soil-5cm }}\right)$ under different weather conditions

a.

\begin{tabular}{|c|c|c|c|c|}
\hline \multicolumn{2}{|c|}{ Items } & Regression equation & $\mathbf{R}^{2}$ & $\mathbf{P}$ \\
\hline \multirow{4}{*}{ Sunny day } & $G$ & $\mathrm{~T}_{\text {soil-5cm }}=0.1397 \mathrm{G}+31.835$ & 0.6196 & 0.0000 \\
\hline & $R n$ & $\mathrm{~T}_{\text {soil- }-5 \mathrm{~cm}}=0.0102 \mathrm{Rn}+30.572$ & 0.1749 & 0.0034 \\
\hline & $L E$ & $\mathrm{~T}_{\text {soil- } 5 \mathrm{~cm}}=0.0145 \mathrm{LE}+30.582$ & 0.1312 & 0.0123 \\
\hline & $H$ & $\mathrm{~T}_{\text {soil- } 5 \mathrm{~cm}}=0.0258 \mathrm{H}+30.976$ & 0.0932 & 0.0369 \\
\hline \multicolumn{5}{|l|}{ b. } \\
\hline \multicolumn{2}{|c|}{ Items } & Regression equation & $\mathbf{R}^{2}$ & $\mathbf{P}$ \\
\hline \multirow{5}{*}{ Overcast day } & $G$ & $\mathrm{~T}_{\text {soil-5cm }}=0.1120 \mathrm{G}+27.299$ & 0.5202 & 0.0001 \\
\hline & $R n$ & $\mathrm{~T}_{\text {soil- }-5 \mathrm{~cm}}=0.0049 \mathrm{Rn}+26.967$ & 0.0942 & 0.0331 \\
\hline & $L E$ & $\mathrm{~T}_{\text {soil-5cm }}=0.0058 \mathrm{LE}+27.012$ & 0.0388 & 0.1748 \\
\hline & $H$ & $\mathrm{~T}_{\text {soil- }-5 \mathrm{~cm}}=0.0087 \mathrm{H}+27.046$ & 0.0152 & 0.3987 \\
\hline & Amount of clouds & $\mathrm{T}_{\text {soil- } 5 \mathrm{~cm}}=-0.6095 \mathrm{AC}+21.527$ & 0.2812 & 0.0008 \\
\hline \multicolumn{5}{|l|}{ c. } \\
\hline \multicolumn{2}{|c|}{ Items } & Regression equation & $\mathbf{R}^{2}$ & $\mathbf{P}$ \\
\hline \multirow{5}{*}{ Rainy day } & $G$ & $\mathrm{~T}_{\text {soil- } 5 \mathrm{~cm}}=0.0596 \mathrm{G}+27.334$ & 0.3027 & 0.0003 \\
\hline & $R n$ & $\mathrm{~T}_{\text {soil-5cm }}=0.0036 \mathrm{Rn}+26.470$ & 0.0924 & 0.0337 \\
\hline & $L E$ & $\mathrm{~T}_{\text {soil-5cm }}=0.0009 \mathrm{LE}+26.823$ & 0.0023 & 0.7450 \\
\hline & $H$ & $\mathrm{~T}_{\text {soil-5 } 5 \mathrm{~cm}}=0.0101 \mathrm{H}+26.488$ & 0.1837 & 0.0021 \\
\hline & Precipitation & $\mathrm{T}_{\text {soil-5cm }}=-1.3911 \mathrm{RF}+27.261$ & 0.1117 & 0.0189 \\
\hline \multicolumn{5}{|l|}{ d. } \\
\hline \multicolumn{2}{|c|}{ Items } & Regression equation & $\mathbf{R}^{2}$ & $\mathbf{P}$ \\
\hline \multirow{4}{*}{ Average value } & $G$ & $\mathrm{~T}_{\text {soil-5cm }}=0.1523 \mathrm{G}+27.968$ & 0.6152 & 0.0000 \\
\hline & $R n$ & $\mathrm{~T}_{\text {soil-5cm }}=0.0107 \mathrm{Rn}+27.513$ & 0.1571 & 0.0048 \\
\hline & $L E$ & $\mathrm{~T}_{\text {soil-5cm }}=0.0126 \mathrm{LE}+27.880$ & 0.0609 & 0.0874 \\
\hline & $H$ & $\mathrm{~T}_{\text {soil- } 5 \mathrm{~cm}}=0.0309 \mathrm{H}+27.437$ & 0.1791 & 0.0025 \\
\hline
\end{tabular}

\section{Surface temperature model}

As overcast and rainy days are rare in the observation period, the observed half-hour scale data of thirteen sunny days, four overcast days, and two rainy days derived from 
sample data are used to establish the land surface temperature model using the stepwise multiple linear regression (Table 7). In these empirical statistical models, soil temperature is chosen as a dependent variable, where each energy components as independent variables (the amount of clouds and rainfall may be included in overcast and rainy days, respectively). Then, the remaining sample data for different weather conditions are applied to validate the models.

Table 7. Soil temperature models for different weather conditions

\begin{tabular}{c|c|c|c|c}
\hline & Equation for multiple linear stepwise regression & $\mathbf{R}^{\mathbf{2}}$ & $\mathbf{p}$ & $\mathbf{F}$ \\
\hline Sunny days & $\mathrm{T}_{\text {soil-5cm }}=3.085 \times 10^{-1} G-2.547 \times 10^{-2} R n+2.004 \times 10^{-3} H+30.427$ & 0.8093 & 0.0000 & 895.19 \\
Overcast days & $\mathrm{T}_{\text {soil-5cm }}=2.469 \times 10^{-1} G-1.662 \times 10^{-2} R n+28.726$ & 0.6623 & 0.0000 & 141.23 \\
Rainy days & $\mathrm{T}_{\text {soil-5cm }}=3.576 \times 10^{-2} G-3.794 \times 10^{-3} R n+1.034 \times 10^{-2} H+28.203$ & 0.2112 & 0.0002 & 8.39 \\
Average & $\mathrm{T}_{\text {soil-5cm }}=3.444 \times 10^{-1} G-3.755 \times 10^{2} R n+1.8470 \times 10^{-2} H+30.455$ & 0.9471 & 0.0000 & 268.77 \\
\hline
\end{tabular}

The established models for different weather conditions are all highly significant ( $\mathrm{p}<$ $0.01)$. However, the models for sunny days $\left(\mathrm{R}^{2}=0.8093\right)$ and for the average condition $\left(\mathrm{R}^{2}=0.9471\right)$ performed best, followed by those for overcast $\left(\mathrm{R}^{2}=0.6623\right)$ and rainy days $\left(\mathrm{R}^{2}=0.2112\right)$ (Table 7). For validation, all simulation results agree with the measured values ( $\mathrm{p}<0.01$, slope $\approx 1$, the mean bias error MBE is little) (Fig. 9). Nonetheless, the sunny model displays a superior $\mathrm{R}^{2}$ value and slope, followed by the overcast and rainy models. These results might be because the sample size for constructing models is different among different weather conditions.

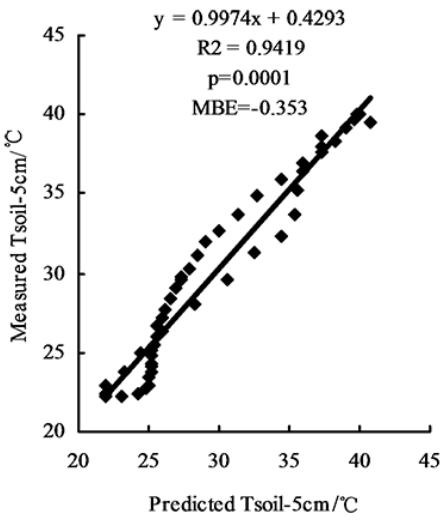

a. sunny day

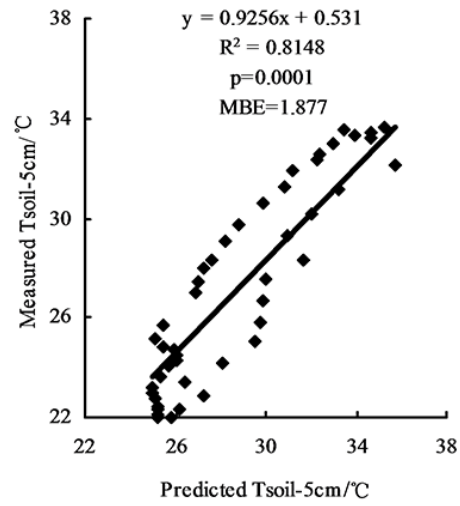

b. overcast day

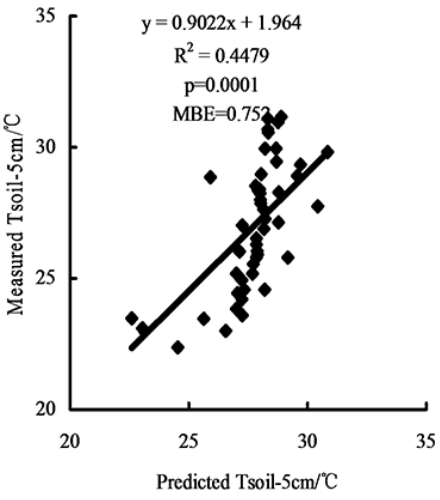

c. rainy day

Figure 9. Comparisons of simulated versus observed (half-hour) land surface temperatures for model validation

$L E$ is excluded in the established models using stepwise multiple linear regression method. This result shows that surface layer soil temperature is mainly affected by dry heat energy factors $(R n, G$, and $H$ ) than to $L E$ under various weather conditions (Table 7). It might be attributed to the fact that the oasis-desert ecotone in Northwest China is outside the East Asian summer monsoon zone. Thus, there is only minimal 
amount of water available for evapotranspiration in the surface layer soil. Furthermore, the precipitation primarily infiltrates into the deeper soil because of coarser soil particle (sandy loam). Consequently, the strong evapotranspiration power does not directly impact the surface layer temperature, but can affect deeper layer temperature. The result is in contrast to that observed in Northeast China and Loess Plateau (Zhang et al., 2012b), where the soil temperature is sensitive to both dry heat energy factors $(R n, G$, and $H$ ) and $L E$ due to monsoon precipitation and loamy or clay soil.

\section{Conclusions}

Unlike the $L E$ reported in most previous studies in the Desert/Gobi, the $L E$ in the current study area is dominant in the energy exchange for all weather conditions. The average value of $L E / R n(59 \%)$ over the observation period is between that of desert and oasis. These results might be explained by the transitional thermal-hydrologic property and the local circulation. The comparisons of energy partitioning among the ten selected station in the Northwest China, show that the general pattern in energy partitioning is significantly affected by the vegetation coverage, as well as climatic condition.

At sunrise and sunset, the conversion of the heat source between the atmosphere and the soil contributes to large peaks or troughs in the energy fluxes curves. At sunrise, the fluctuation amplitude of $L E / R n$ is the greatest among all of the curves. As a result of different radiation intensities and sunshine hours, there is a difference in the time-point at which energy fluxes begins to change violently in mornings and evenings among the four different weather conditions.

The correlations between each energy component and soil temperature imply that they are all highly significant for all weather conditions. However, they are ordered as follows: $G>R n>H>L E$. The correlations of $G, R n, L E$, and soil temperature under different weather conditions can be ranked as follows: sunny days > average value > overcast days > rainy days. Moreover, the response sensitivity (regression coefficients) of soil temperature to change in each energy component indicates that the average and sunny conditions are equal, followed by the overcast and rainy conditions.

The prediction models for land surface temperature without $L E$ under different weather conditions imply that soil surface layer temperature is mainly affected by dry heat energy factors $(R n, G$, and $H)$ and less sensitive to the hygrothermal energy factor $(L E)$ in the oasis-desert ecotone. It is difficult for us to make an in-depth, detailed analysis on the mechanism of land surface process in the oasis-desert ecotone due to the limited temporal coverage. Thus, it's necessary to accumulate longer time series of observational data for refining our findings.

Acknowledgements. This study is supported by Major Science and Technology Program for Water Pollution Control and Treatment (2017ZX07203002-02), National Natural Science Foundation of China (41701031), Water Resources Science and Technology Program of Jiangsu Water Resources Department (2017002ZB), and Talents-Import Program in Nanjing Institute of Geography and Limnology (NIGLAS2017QD06).

\section{REFERENCES}

[1] Bowen, I. S. (1926): The ratio of heat losses by conduction and by evaporation from any water surface. - Physical Review 27: 779. 
[2] Burakowski, E., Tawfik, A., Ouimette, A., Lepine, L., Novick, K., Ollinger, S., Zarzycki, C., Bonan, G. (2018): The role of surface roughness, albedo, and Bowen ratio on ecosystem energy balance in the Eastern United States. - Agricultural and Forest Meteorology 249: 367-376.

[3] Dugas, W. A., Mayeux Jr, H. S. (1991): Evaporation from rangeland with and without honey mesquite. - Journal of Range Management 161-170.

[4] Foken, T. (2008): The energy balance closure problem: an overview. - Ecological Applications 18: 1351-1367.

[5] Foken, T., Wimmer, F., Mauder, M., Thomas, C., Liebethal, C. (2006): Some aspects of the energy balance closure problem. - Atmospheric Chemistry and Physics 6: 4395-4402.

[6] Gage, E. A., Cooper, D. J. (2017): Urban forest structure and land cover composition effects on land surface temperature in a semi-arid suburban area. - Urban Forestry \& Urban Greening 28: 28-35.

[7] Gualtieri, G. (2018): Surface turbulence intensity as a predictor of extrapolated wind resource to the turbine hub height: method's test at a mountain site. - Renewable Energy 120: 457-467.

[8] Halldin, S., Gottschalk, L., van de Griend, A. A., Gryning, S.-E., Heikinheimo, M., Högström, U., Jochum, A., Lundin, L.-C. (1998): NOPEX - a northern hemisphere climate processes land surface experiment. - Journal of Hydrology 212: 172-187.

[9] Luo, D., Jin, H., Marchenko, S. S., Romanovsky, V. E. (2018): Difference between nearsurface air, land surface and ground surface temperatures and their influences on the frozen ground on the Qinghai-Tibet Plateau. - Geoderma 312: 74-85.

[10] Mathew, A., Khandelwal, S., Kaul, N., Chauhan, S. (2018): Analyzing the diurnal variations of land surface temperatures for surface urban heat island studies: Is time of observation of remote sensing data important? - Sustainable Cities and Society 40: 194-213.

[11] Oncley, S. P., Foken, T., Vogt, R., Kohsiek, W., DeBruin, H., Bernhofer, C., Christen, A., Van Gorsel, E., Grantz, D., Feigenwinter, C. (2007): The energy balance experiment EBEX2000. Part I: overview and energy balance. - Boundary-Layer Meteorology 123: 1-28.

[12] Osann Jochum, M. A., de Bruin, H. A. R., Holtslag, A. A. M., Belmonte, A. C. (2006): Area-averaged surface fluxes in a semiarid region with partly irrigated land: Lessons learned from EFEDA. - Journal of Applied Meteorology and Climatology 45: 856-874.

[13] Pal, S., Ziaul, S. (2017): Detection of land use and land cover change and land surface temperature in English Bazar urban centre. - The Egyptian Journal of Remote Sensing and Space Science 20: 125-145.

[14] Peacock, C., Hess, T. (2004): Estimating evapotranspiration from a reed bed using the Bowen ratio energy balance method. - Hydrological Processes 18: 247-260.

[15] Pearson, K. (1895): Note on regression and inheritance in the case of two parents. Proceedings of the Royal Society of London 58: 240-242.

[16] Sellers, P., Hall, F., Ranson, K. J., Margolis, H., Kelly, B., Baldocchi, D., den Hartog, G., Cihlar, J., Ryan, M. G., Goodison, B. (1995): The boreal ecosystem-atmosphere study (BOREAS): an overview and early results from the 1994 field year. - Bulletin of the American Meteorological Society 76: 1549-1577.

[17] Si, J., Feng, Q., Zhang, Y., Chang, Z., Zhang, K. (2010): Research on evapotranspiration and energy budget of phragmites australis stand in Oasis. - Arid Zone Research 27: 160-168.

[18] Spittlehouse, D., Black, T. (1980): Evaluation of the Bowen ratio/energy balance method for determining forest evapotranspiration. - Atmosphere-Ocean 18: 98-116.

[19] Tiyip, T., CUI, J.-y., DING, J.-1. (2005): Study on the means of groundwater distribution beneath the oasis-desert ecotone in an arid area by using thermal infrared data. - Arid Land Geography 2: 025.

[20] Todd, R. W., Evett, S. R., Howell, T. A. (2000): The Bowen ratio-energy balance method for estimating latent heat flux of irrigated alfalfa evaluated in a semi-arid, advective environment. - Agricultural and Forest Meteorology 103: 335-348. 
[21] Uddin, J., Hancock, N. H., Smith, R. J., Foley, J. P. (2013): Measurement of evapotranspiration during sprinkler irrigation using a precision energy budget (Bowen ratio, eddy covariance) methodology. - Agricultural Water Management 116: 89-100.

[22] Urqueta, H., Jódar, J., Herrera, C., Wilke, H.-G., Medina, A., Urrutia, J., Custodio, E., Rodríguez, J. (2018): Land surface temperature as an indicator of the unsaturated zone thickness: A remote sensing approach in the Atacama Desert. - Science of the Total Environment 612: 1234-1248.

[23] Wagner, M. J., Bladon, K. D., Silins, U., Williams, C. H., Martens, A. M., Boon, S., MacDonald, R. J., Stone, M., Emelko, M. B., Anderson, A. (2014): Catchment-scale stream temperature response to land disturbance by wildfire governed by surface-subsurface energy exchange and atmospheric controls. - Journal of Hydrology 517: 328-338.

[24] Wang, H., HU, Z., Ma, W., LI, D. (2008): The seasonal variation of microclimate characteristics and energy transfer in the surf ace layer over Dingxin Gobi. - Chinese Journal of Atmospheric Sciences 32: 1458-1470.

[25] Wang, S., Zhang, Q., Wei, G. (2005): Analyses on characters of surface radiation and energy at oasis-desert transition zone in Dunhuang. - Plateau Meteorology 24: 556-562.

[26] Wang, S., Ma, Q., Ding, H., Liang, H. (2018): Detection of urban expansion and land surface temperature change using multi-temporal landsat images. - Resources, Conservation and Recycling 128: 526-534.

[27] Wang, Y., Ali, M., He, Q., Yang, X., Huo, W., Zhang, J. (2014): Research on surface energy budget in the north margin of Taklimakan Desert. - Desert and Oasis Meterorology 8: 34-41.

[28] Weisberg, S. (1985): Applied Linear Regression. - Wiley, New York, pp. 371-372.

[29] Wiernga, J. (1993): Representative roughness parameters for homogeneous terrain. Boundary-Layer Meteorology 63: 323-363.

[30] Xystrakis, F., Psarras, T., Koutsias, N. (2017): A process-based land use/land cover change assessment on a mountainous area of Greece during 1945-2009: Signs of socioeconomic drivers. - Science of the Total Environment 587-588: 360-370.

[31] Yang, X., Zhang, Q., Wang, R., Ma, P., Yang, Q., Liu, H. (2004): Experimental study on surface energy balance over Loess Plateau of middle part Gansu in summer. - Plateau Meteorology 23: 828-834.

[32] Yaşar Korkanç, S. (2018): Effects of the land use/cover on the surface runoff and soil loss in the Niğde-Akkaya Dam Watershed, Turkey. - Catena 163: 233-243.

[33] Zhang, K., Wang, R., Zhang, Q., Si, J., Yang, Q., Liu, H., Wang, H. (2007): Characteristics of surface radiation and energy balance as well microclimate within oasisdesert ecotone of Zhangye on typical clear days in summer. - Journal of Desert Research 27: 1055-1061.

[34] Zhang, Q., Cao, X. (2003): The influence of synoptic conditions on the averaged surface heat and radiation budget energy over desert or Gobi. - Chinese Journal of Atmospheric Sciences 27: 245-254.

[35] Zhang, Q., Li, H., Zhao, J. (2012a): Modification of the land surface energy balance relationship by introducing vertical sensible heat advection and soil heat storage over the Loess Plateau. - Science China Earth Sciences 55: 580-589.

[36] Zhang, Q., Zeng, J., Zhang, L. (2012b): Characteristics of land surface thermalhydrologic processes for different regions over North China during prevailing summer monsoon period. - Science China Earth Sciences 55: 1872-1880.

[37] Zhang, Q., Zhang, L., Huang, J., Zhang, L. Y., Wang, W. Y., Sha, S. (2014): Spatial distribution of surface energy fluxes over the Loess Plateau in China and its relationship with climate and the environment. - Sci. China-Earth Sci. 57: 2135-2147.

[38] Zheng, H., Wang, J., Maitani, T., Ohtaki, E., Huang, Z., Zhao, S. (2000): Some characteristics of energy exchange at the underlying surface of desert and oasis in Hexi Corridor. - Acta Ecologica Sinica 20: 88-92. 